\title{
Influence of Through-Thickness Pinning on Composite Shear Properties
}

\author{
Romain Maurin ${ }^{1}$, Christophe Baley ${ }^{1}$, Denis D. R. Cartié ${ }^{2}$ and Peter Davies ${ }^{3}$ \\ ${ }^{1}$ LIMATB, Université de Bretagne Sud, 56321, Lorient cedex, France \\ 2 Polymer Composites Centre, Cranfield University, Bedford, MK3 OAL, UK \\ ${ }^{3}$ IFREMER, Centre de Brest, 29280, Plouzané, France \\ *: Corresponding author : Peter Davies, email address : peter.davies@ifremer.fr
}

\begin{abstract}
:
This paper describes results from tests to examine the influence of through-thickness pinning on inplane shear behaviour, measured by tensile loading of $\pm 45^{\circ}$ specimens. Samples were produced by both aeronautical and marine manufacturing processes. As few previous studies have investigated pinning of marine composites these were also subjected to out-of-plane shear delamination tests. For both carbon/epoxy laminates the pins reduce the apparent in-plane shear modulus and strength. Pins modify the strain field measured by full-field image analysis, and slow damage development. A new damage mechanism, transverse pin cracking, was observed.
\end{abstract}

Keywords: Z-pinning ; Shear ; Mode II ; Damage ; Acoustic emission

\section{Introduction}

Through-thickness reinforcement or "Z-pinning" consists of inserting composite pins into a laminate in the z-direction before cure. It can be used to prevent delamination in critical laminate zones, such as close to open holes, and is a most promising method to reinforce the out-of-plane properties of prepreg laminates [1-3]. However, it inevitably reduces the in-plane properties. Various authors have presented results showing that pinned laminates exhibit a loss in tensile and compression properties [3-8], but little work has been performed to evaluate how pinning affects shear properties. In the present study, the influence of pins on damage and local strain in composites was tested under inplane shear. Two types of carbon/epoxy material were studied: a material made by an aeronautical manufacturing process (autoclave), and a marine composite (fabrication under vacuum) in order to evaluate the differences between them. There have been several previous studies of the out-of-plane properties of aeronautical pinned composites, but none have investigated the use of pinning in marine composites. Tensile tests on specimens with fibres oriented at $\pm 45^{\circ}$ to the loading direction were used to measure in-plane properties. Mode II (out-of-plane shear) delamination tests were also performed on unidirectional marine composites, to examine their out-of-plane shear behaviour. 


\section{MATERIALS AND METHODS}

\section{Materials}

Two materials have been studied, each produced by a different manufacturing method.

The reference material, representative of aeronautical production, was produced with unidirectional carbon fibre/epoxy prepreg (IMS/924) in an autoclave at $180^{\circ} \mathrm{C}$. The prepreg was laid at $\pm 45^{\circ}$ with mirror symmetry for a total thickness of $1.8 \mathrm{~mm} .4 \%$ pins (by volume) were inserted in the plate and compared with unpinned $(0 \%)$ plate results. A large pinned area was produced, sufficient to cut out completely pinned and unpinned specimens. Fibre volume fraction of the unpinned material was $60 \%$.

The marine composite samples were prepared in a boatyard using Hexcel woven EQ M10/CHS-12k prepreg cured under vacuum at $125^{\circ} \mathrm{C}$. A panel $1.8 \mathrm{~mm}$ thick with mirror symmetry was manufactured with two strips of pins in a square array, of densities ( $2 \%$ and $4 \%)$.

This marine manufacturing method was also used to produce a unidirectional panel $\left(0^{\circ}\right)$, in order to dispose of three series of mode II delamination test samples with no, 2 and 4\% pins. This was produced from prepreg, and cured at the same time as the woven fibre panel, thickness was $3.9 \mathrm{~mm}$ and a starter film was created by including a $10 \mu \mathrm{m}$ thick PTFE sheet at mid-thickness. The first line of pins was located approximately $5 \mathrm{~mm}$ from the end of the starter film. Figure 1 shows the insertion of the pins using an ultrasonic pistol. Fibre volume fraction of the unpinned region was $60 \%$. The pins studied here are $0.28 \mathrm{~mm}$ diameter carbon fibre/BMI reinforced pultruded rods. Their properties and insertion have been described in detail previously $[1,2]$.

\section{In plane shear test}

An Instron 8803 test machine with a $50 \mathrm{kN}$ load cell was used for all shear tests, following the ASTM standard D3518M procedure based on the original work by Rosen [9]. This involves testing $25 \times 90 \times 1.8 \mathrm{~mm}^{3} \pm 45^{\circ}$ specimens in tension to determine in-plane shear behaviour. The loading rate was $2 \mathrm{~mm} / \mathrm{min}$. At least 4 specimens were tested for each pinning condition.

An MTS biaxial extensometer and an optical whole-field measurement system (ARAMIS system from GOM GmbH) were used to measure in-plane strains. It was verified in a preliminary study that the average strain obtained by the latter was equal to the value given by the former.

Damage development was studied by acoustic emission (MISTRAS system from Euro Physical Acoustic). Figure 2 shows the test set-up. 
Some tensile tests were also performed on small $\left(25 \times 90 \times 1.8 \mathrm{~mm}^{3)} \pm 45^{\circ}\right.$ specimens in a scanning electron microscope, using a Deben microtester with a $250 \mathrm{~N}$ load cell.

\section{Mode II delamination test}

An Instron 4801 test machine with a $10 \mathrm{kN}$ load cell was used with a 4 point bending fixture (4 end-notched flexure (4ENF)) (Figure 3) [10] to characterize the resistance to delamination under out-of-plane shear loading. There is no standard procedure available for this test [11]. $150 * 19 * 3.90 \mathrm{~mm}^{3}$ samples with a $50-60 \mathrm{~mm}$ long starter film were tested. The upper loading span was $60 \mathrm{~mm}$, the support span $\mathrm{S}$ was $100 \mathrm{~mm}$. The samples were loaded under crosshead displacement control at $1 \mathrm{~mm} \mathrm{~min}^{-1}$, crack propagation was in the fibre direction.

$\mathrm{G}_{\mathrm{IIC}}$ can be calculated by the beam theory expression [12]:

$$
G_{\text {IIC }}=\frac{P^{2}}{2 b} \frac{3 L^{2}}{32 E I}
$$

\section{Equation 1}

With $\mathrm{P}$ the load, $\mathrm{L}$ the distance between the upper and lower loading points, $\mathrm{b}$ the sample width, E the modulus and I the second moment of inertia. Precise crack length monitoring is hard to achieve, so the crack length used in this article was calculated by Equation 2, where $\mathrm{a}_{\text {cal }}$ is the crack length, $\mathrm{S}$ the distance between the two lower load points and $\delta$ is the deflection of the beam due to the cross head displacement [12].

$$
\bar{u}_{i \leq t}=\frac{1}{3}\left[\frac{32 E I \delta}{P L^{2}}+\frac{10}{3} L-S\right]
$$

\section{Equation 2}

The crack length values obtained by the calculation were checked by video measurements using images of the specimen edge taken during tests.

Results are plotted as R-curves, strain energy release rate versus effective crack length. A minimum of 4 specimens were tested for each pinning condition.

\section{RESULTS}

\section{IN PLANE SHEAR}

\section{Shear Modulus variation due to pins}

A previous numerical study of $\pm 45^{\circ}$ composites predicted a $9 \% \mathrm{G}_{\mathrm{xy}}$ modulus loss for $2 \%$ pins [5]. In the present study, the loss was $22 \%$ for $4 \%$ pins for the aeronautical plate, and up to $50 \%$ for $4 \%$ pins in the marine composite. The tensile test curve shapes are quite different for the two plates, Figure 4, these differences show the strong influence of manufacturing route on shear behaviour. It may also be noted that increasing the pin density results in higher standard deviation, Figure 5. 


\section{Strength variation due to pins}

Fig 6 shows $\tau_{12} \max$ values. These are not the stresses at break, but the values at $5 \%$ strain, as specified in the ASTM standard. This value corresponds to $1.5^{\circ}$ fibre rotation. The aeronautical panels show considerably higher $\tau_{12} \max$ values than the marine materials, both with and without pins. The loss is about $12 \%$ for both when $4 \%$ pins are added.

\section{OUT-OF-PLANE SHEAR}

\section{Mode II delamination}

The load-deflection curves for the unidirectional marine composites show that the crack propagation starts for a load equal to $1500 \mathrm{~N}$ for both the unpinned and the $2 \%$ pinned samples (Fig. 7). The propagation observed for both types of samples was stable, but with a higher load for the pinned one. The 4ENF fixture produces more stable propagation than the 3ENF configuration [12], the propagation in tests performed previously by Cartié et al [1] on pinned samples using a 3ENF fixture was unstable.

The 4\% pinned samples did not show any propagation before specimen flexural failure. In this case the pins increased the mode II fracture toughness sufficiently to change the failure mode.

The unpinned and $2 \%$ pin $\mathrm{G}_{\text {IIC }}$ curves begin at similar values, because the initiation occurs in the unpinned zone (Fig. 8 a and b). Unpinned specimen Rcurves show a constant $\mathrm{G}_{\text {IIc }}$ value until the crack approaches the upper loading pin. $2 \%$ pin specimen curves are slightly different. $\mathrm{G}_{\text {IIc }}$ increases by steps, as the crack approaches the pins. The value measured when the crack reaches the first pin is twice the initiation one. The energy continues to rise after the crack passes the first row of pins.

The $4 \%$ pinned composite curves rise faster than the other curves up to the sample failure in flexure. The crack never reaches the pinned zone (Fig. 8 b), suggesting that there may be an interaction with the damage zone developing in front of the crack.

The $2 \%$ pinned samples fracture surfaces were examined in the scanning electron microscope. Different mechanisms were noted:

- pin pull-out (Fig. 9)

- pin shear (Fig. 10)

- the thickness variation due to the constraints caused by pinning creates voids, and interlaminar cracks are noted below the main crack plane (Fig.11).

\section{DISCUSSION}

\section{Influence of pins on laminate structure}

The insertion of pins resulted in an increase in the laminate thickness for both types of manufacture. For example, the marine composite thickness swelled from 
$1.83 \mathrm{~mm}$ for the unpinned part to $2.30 \mathrm{~mm}$ for the $4 \%$ pinned area. This swelling effect has been described previously, it is related to the pin diameter and density [6]. This thickness increase is not caused by material addition, except for the small volume of pins. It is the result of the pin stiffness in the z-direction, which limits compaction during manufacturing [8].

Pinning creates fibre waviness, and eye-shaped resin rich zones next to pins, Fig. 12. Craig et al showed that the local waviness could be up to $14^{\circ}$ for a $2 \%$ pinned zone [4]. It increases linearly with the pin diameter ( $1^{\circ}$ for $\left.0.07 \mathrm{~mm}\right)$. Half of the volume of a $4 \%$ pinned zone is perturbed by the waviness [6]. The angle between the fibres and the pinning row increases the fibre waviness [6], the in-plane shear specimens tested here present the maximum angle: $45^{\circ}$.

As noted above, the local fibre content is highly perturbed by the pins. In order to subtract a part of this effect, the thickness variation near the pinned zone, the force flux has been studied. Figures 13 and 14 show the stiffness and force fluxes, calculated by simply removing the thickness from the usual modulus and stress calculations, as a function of the pin density.

The modulus decreases for the marine plate with increasing pin density, while the aeronautical plate modulus increases slightly. The force flux increases for both materials. This suggests that the out of plane reinforcement acts in a different way for the marine composites, though there is considerable scatter for these materials. The strength decrease noted in Fig. 6 is not visible on the force flux plot above, which indicates that the reduction noted was simply due to the thickness increase. For the aeronautical material, the unpinned specimens break at an average load flux equal to $170 \mathrm{Nmm}^{-1}$, whereas the $4 \%$ pinned specimens fail at a load flux equal to $195 \mathrm{~N} \mathrm{~mm}^{-1}$. For the marine composite, which was not pinned over all the surface, the fracture never appeared in the pinned area even when the tensile test grip was close to the pinned zone. This can be explained by the delamination mechanism which is usually observed during this test when the fibres rotate, but whose propagation was blocked in the region reinforced by the pins, resulting in higher force flux values for pinned specimens of both types of material [6].

\section{Full field strain analysis}

The $\pm 45^{\circ}$ tensile test full field strain is generally heterogeneous when measured at a local scale [13], the strain field depends on the reinforcement geometry. For the $\pm 45^{\circ}$ composites tested here without pins the maximum strain is parallel to the fibres, Figure 15. Figure 16 shows the same test and global strain level on a composite with two distinct zones: an unpinned zone and a $4 \%$ pinned zone. The strain field is highly heterogeneous; the unpinned field in the upper part of the picture and the pinned area where the strain is lower and more uniform in the lower part. This clearly illustrates the influence of the pins on the strain field. In order to quantify these observations, the local strain standard deviation is plotted versus average strain for the aeronautical plate (Fig. 17). This parameter describes the strain heterogeneity. For the pinned laminate the strain was measured in the pinned region only. For both composites, the relation between the average strain and the standard deviation presents an exponential trend, but the values are significantly lower for the pinned composite. For a $4 \%$ global strain, the standard deviation is twice as high for the unpinned laminate. This means that the pins homogenise the strain field, perhaps by blocking the fibre rotations. 


\section{Damage}

For the damage study only the aeronautical samples were used. The damage threshold was defined by the first events localised between the two transducers at the two ends of the specimen (Fig. 18) This characteristic did not change with the addition of pins, it was recorded at a nominal stress of $13 \mathrm{MPa}$. The only difference noted was the total number of acoustic events recorded, which was significantly higher for the unpinned composites.

The acoustic emission energy sum shows the difference between the damage development in the two materials. The plot of this parameter against time for the unpinned composite showed that there were mainly low energy events until the middle of the test. After this point, the sum increased linearly up to the break. The same plot for the pinned composite showed a different trend after the first fifth of the test. During the second fifth of the test, the damage energy sum increased strongly, and then increased in a linear way up to failure.

The non-summed acoustic emission energy provides some additional information (Fig. 18). For the unpinned composites, most events are of low energy. After the first half of the test, some high energy events appear in addition to the low energy ones. For the pinned composite, there are 3 damage zones. The first fifth of the curve shows the same low energy events as for the unpinned sample. During the second fifth, some additional high energy events are recorded. During the third damage period, the low energy threshold level increases. All the observations noted in terms of energy are also recorded with the signal amplitude data.

The definition of a damage mechanism by precise acoustic parameter intervals is controversial, but the correlations frequently proposed (e.g. [14,15]) are:

- Low amplitude events: matrix damage

- Medium amplitude events: fibre-matrix interface damage

- High amplitude events: fibre failure.

Here the damage begins in the same way for both composites, low energy and low amplitude. This is mainly matrix damage, which is why the damage thresholds are equal for pinned and unpinned materials. The differences start in the second damage zone for the pinned composite, with high energy and high amplitude events. In situ tensile tests in the SEM were used to identify mechanisms during this damage period. The SEM pictures show matrix failure in the pins for these loads, Fig. 19. During all the high energy events period, some cracks appear in the pins. The cracks are always perpendicular to the tensile force, which means that pin damage is transverse cracking of the unidirectional pultruded pins.

After this second damage zone, the SEM pictures show some crack propagation, but no more crack initiation in the pins. For the third damage zone, the amplitude threshold rises. That probably means that the damage which initially involved the matrix becomes debonding. This can be interfacial, interlaminar or pin-composite debonding. The SEM pictures show some intralaminar cracks which, from time to time, connect to cracks in the pins. They also show some pin debonding and some delamination at the test end. $\mathrm{Z}$ pins cannot block the delamination initiation, but strongly influence its propagation. The damage change from matrix to debonding is due to blocking of the fibre rotation by the pins, as noted previously. 


\section{CONCLUSION}

In this work, the shear (in-plane and out of plane) behaviour and damage of composites strengthened by through-thickness pins has been studied. First, the influence of pinning on two types of composites has been compared, one aeronautical and one marine. The shear properties differ, and the pins appear to reduce the in-plane properties, as was previously reported in the literature for other fibre orientations. A $20 \%$ to $50 \%$ decrease was measured for the apparent shear modulus for $4 \%$ pins. This loss is due to the fibre waviness, resin rich zones, and the modified compaction close to the pins.

A $12 \%$ apparent strength loss was noted for the $4 \%$ pinned composites, but this is an artefact due to the local thickness variation, which is superior to the material addition and is attributed to the limited compaction near the pins. If the local thickness is not taken into account (force flux values), no strength loss is measured.

Damage under in-plane shear loading begins in the same way for both composites (pinned and unpinned), by matrix damage above a $13 \mathrm{MPa}$ shear stress. The difference between the unpinned and pinned materials starts for $\tau=20 \mathrm{MPa}$. This corresponds to the stress for which crack initiation occurs within the pins. After this initiation, the cracks propagate and the global pinned composite damage changes from matrix damage to debonding (interfacial, pins-matrix, intralaminar...). However, the pins prevent delamination up to the very end of the test.

Mode II delamination tests indicate that $2 \%$ pins significantly increase (double) the resistance to interlaminar crack propagation. When $4 \%$ pins were added no propagation occurred, the specimens failed in flexure. If the pins are used as local strengthening, they will limit the delamination propagation, the large increase in out-of-plane properties will be accompanied by a small in-plane shear modulus reduction. 


\section{REFERENCES}

1. Partridge I.K., Cartié D.D.R., Bonnington T., Manufacture and performance of Z-pinned composites. In Advanced polymeric materials: structure-property relationships: S. Advani and G. Shonaike, Editors, CRC Press (2003)

2. $\quad$ Partridge I.K., Cartié D.D.R., Composites Part A 36, (2005) 55-64

Mouritz A.P., Composites: Part A 38 (2007) 2383-2397

4. Steeves C.A., Fleck N. A., International Journal of Solids and Structures 43 (2006) 31973212

5. $\quad$ Grassi M., Zhang X., Meo M., Composites: Part A 33 (2002) 1653-1664

6. Mouritz A.P., Composites Science and Technology 67 (2007) 3110-3120

7. Chang P., Mouritz A.P., Cox B.N., Composites: Part A 38 (2007) 244-251

8. $\quad$ Chang P., Mouritz A.P., Cox B.N., Composites: Part A 37 (2006) 1501-1513

9. $\quad$ Rosen B.W, J. Compos. Mater 6 (1972) 552-554

10. Schuecker C., Davidson B.D., Composites Science and Technology, 60 (2000) 2137-2146

11. Brunner A.J., Blackman B.R.K., Davies P, Engineering Fracture Mechanics, June 2008, Vol. 75 (9) : 2779-279

12. Cartié D., Davies P., Peleau M,. Partridge I.K, Composites: Part B, 37 (2006) 292-300

13. Gliesche K., Hübner T., Orawetz H., Composites Science and Technology 65 (2005) 163-171.

14. Meraghni F, Desrumaux F, Benzeggagh ML, Composites Science and Technology Volume 62, Issue 16, December 2002, Pages 2087-2097

15. Godin N., Huguet S., Gaertner R., Composite Structures, Volume 72, Issue 1, January 2006, Pages 79-85 

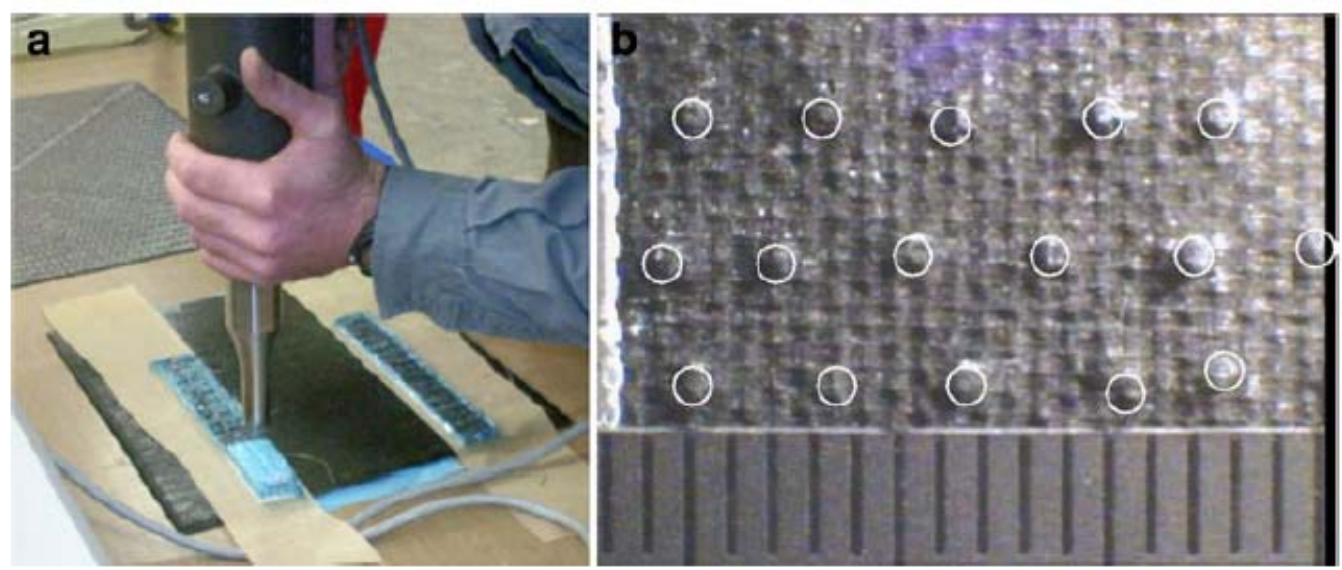

Fig. 1 Through-thickness pins. a Insertion of pins into unidirectional prepreg lay-up before cure, b offset square pin arrangement ( $2 \%$ density) three lines across specimen width. White circles indicate pin positions

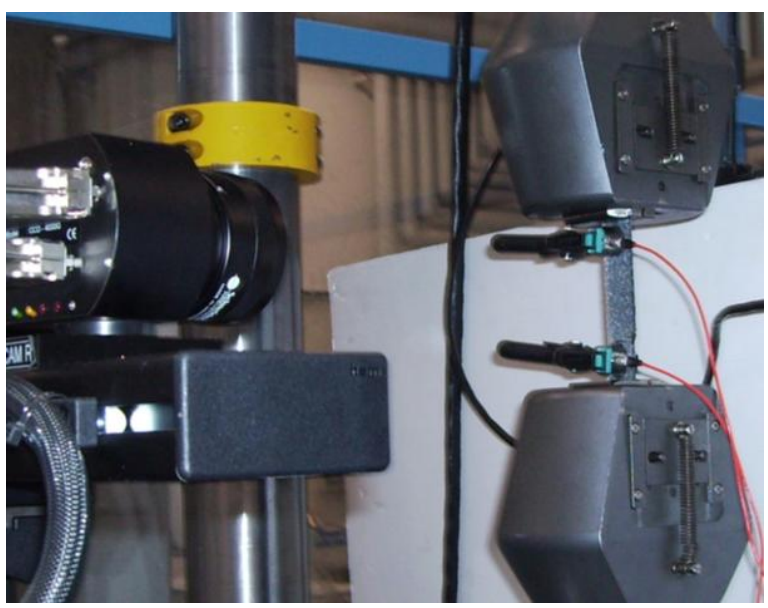

Figure 2 Test set-up for in-plane shear

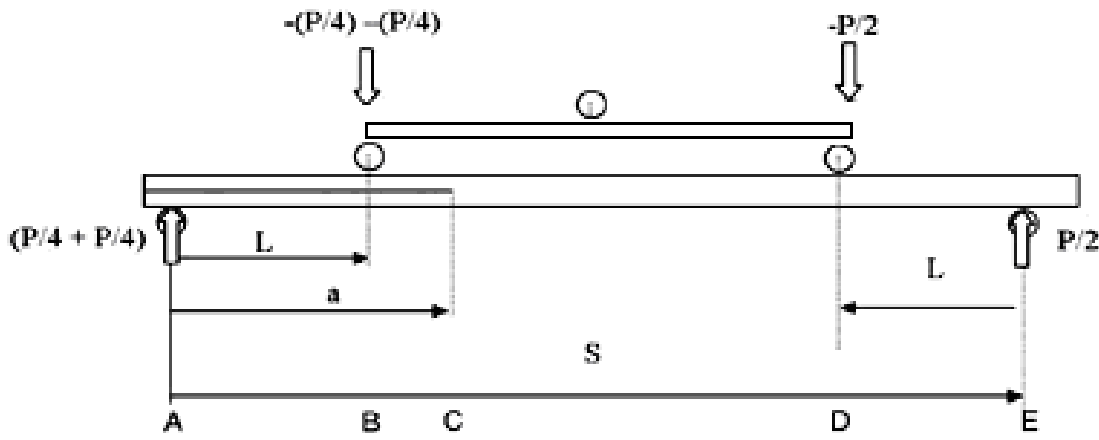

Figure 3. Mode II 4ENF test 

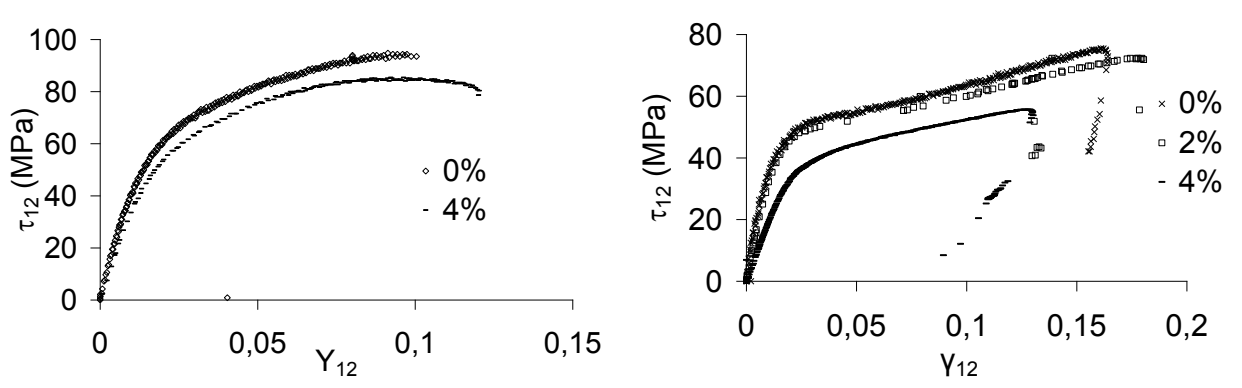

Figure 4. Tensile test plots a) aeronautical b) marine composites
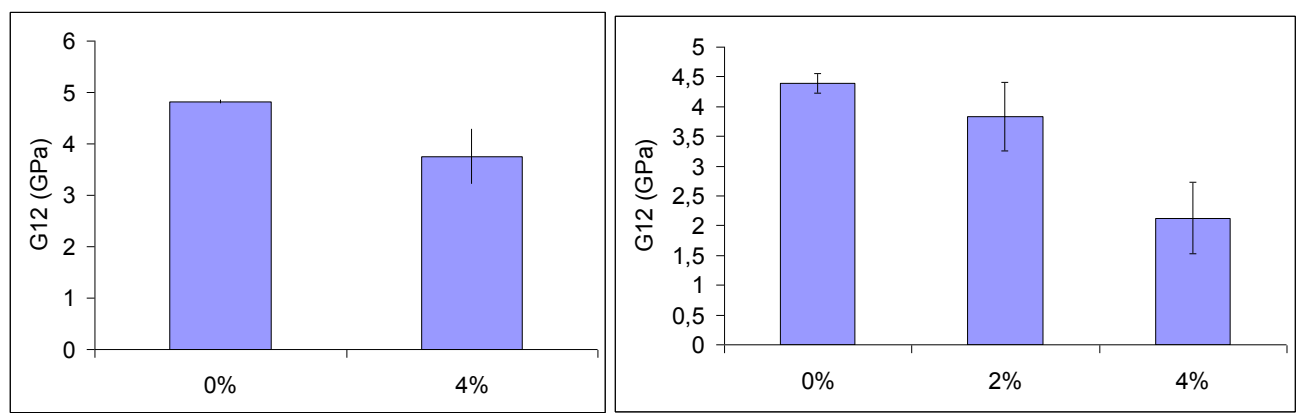

Figure 5. Shear Modulus variation a) aeronautical b) marine composites. Error bars indicate \pm one standard deviation.
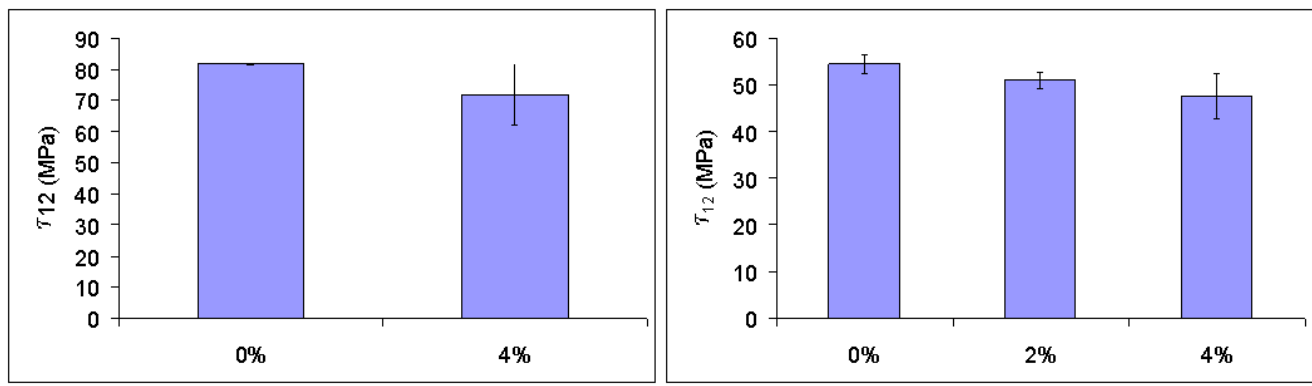

Figure 6. $\tau_{12 \text { max }}$ variation for $5 \%$ strain a) aeronautical b) marine composite. Error bars indicate \pm one standard deviation.

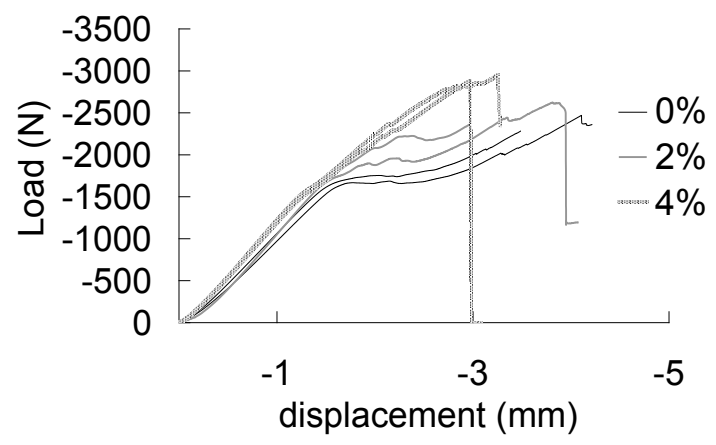

Figure 7. Load-displacement curves, six 4ENF specimens. 

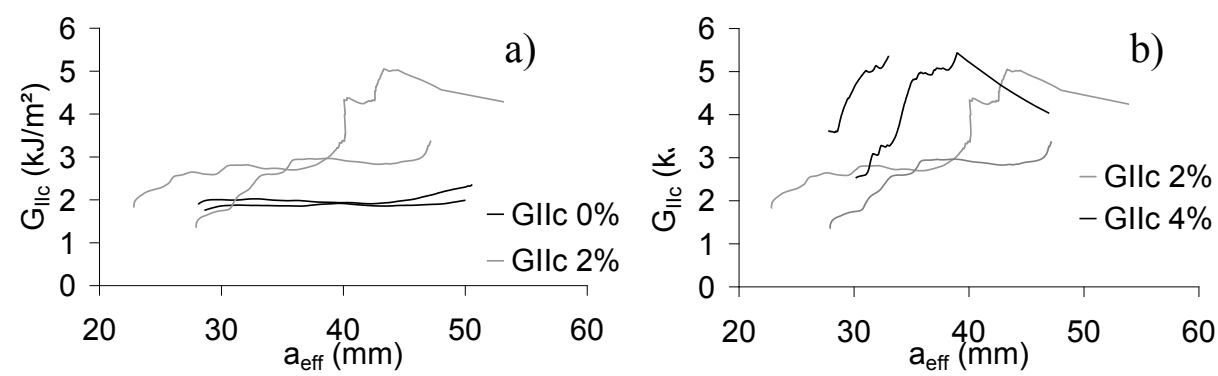

Figure 8. R curves a) $0 \%$ and $2 \%$ b) $2 \%$ and $4 \%$
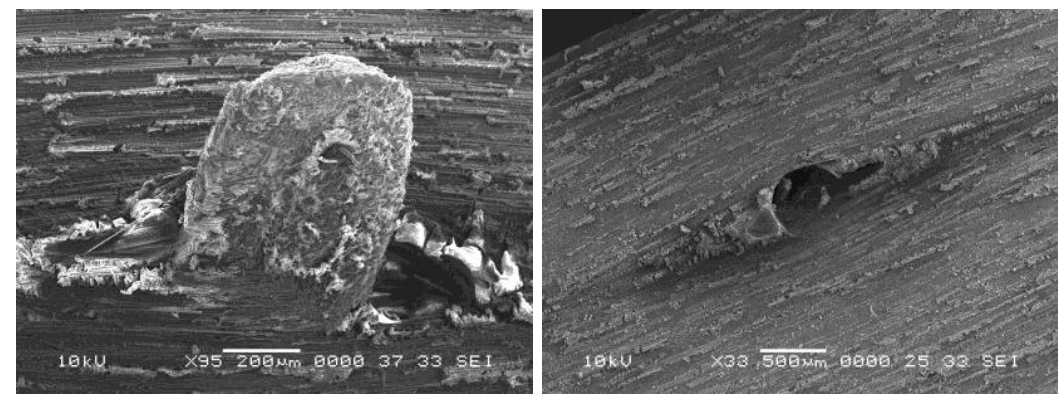

Figure 9. Mode II fracture surface, $2 \%$ pin density. Protruding pin and hole left after pull out during crack propagation
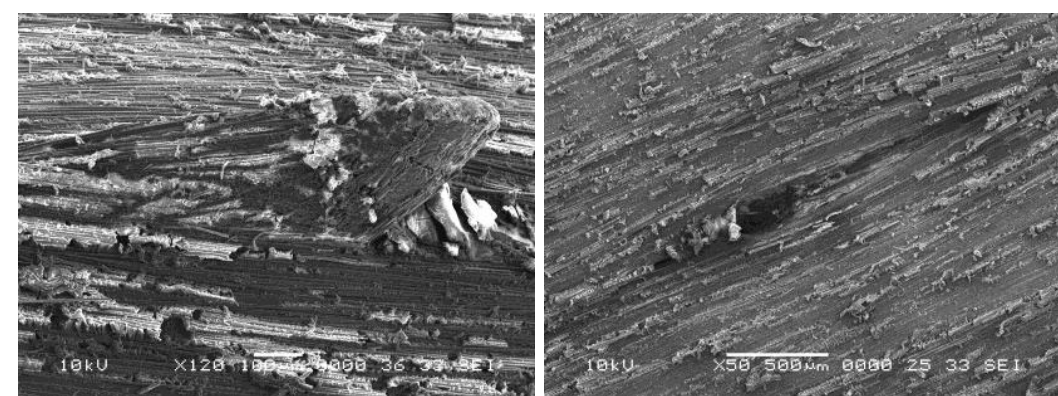

Figure 10. Mode II fracture surface, $2 \%$ pin density. Sheared pin and corresponding hole.

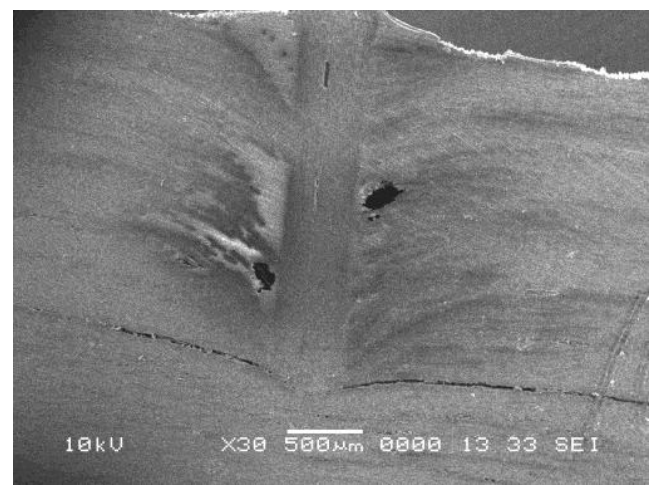

Figure 11. Section through specimen showing voids close to pins and delamination. 


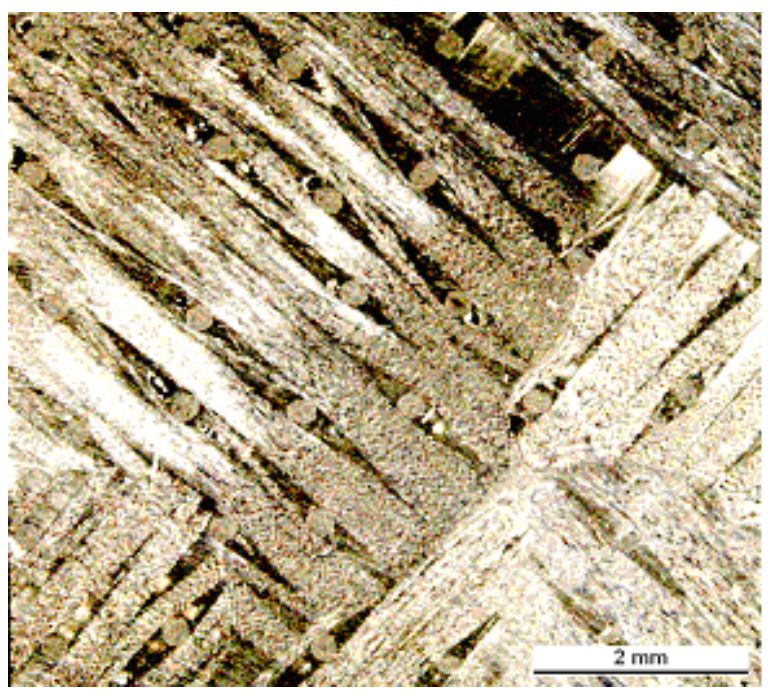

Figure 12. Pinned zone in woven marine composite

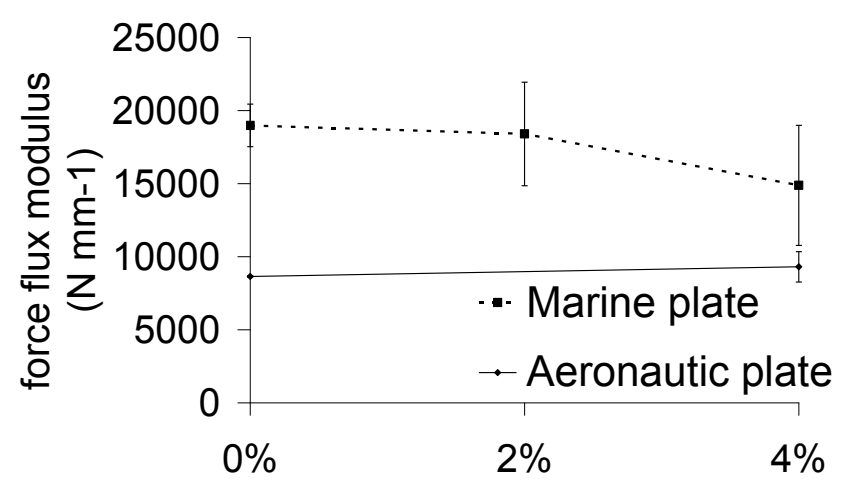

Figure 13. Modulus flux variation as function of the pin density

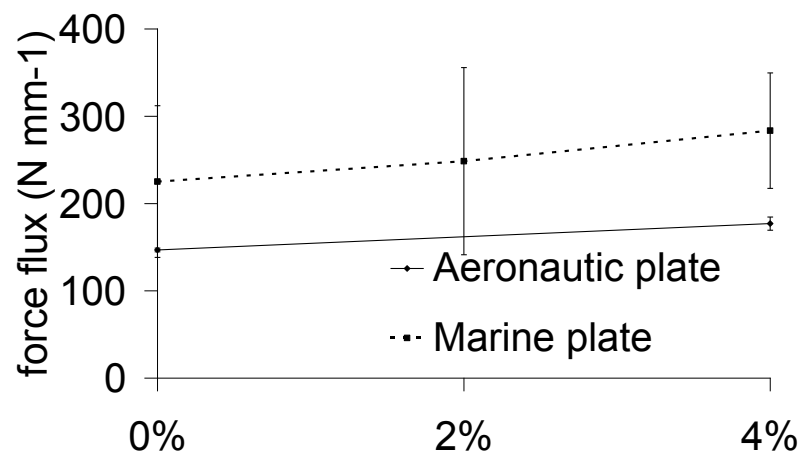

Figure 14. Force flux for $5 \%$ strain, variation as a function of the pin density 


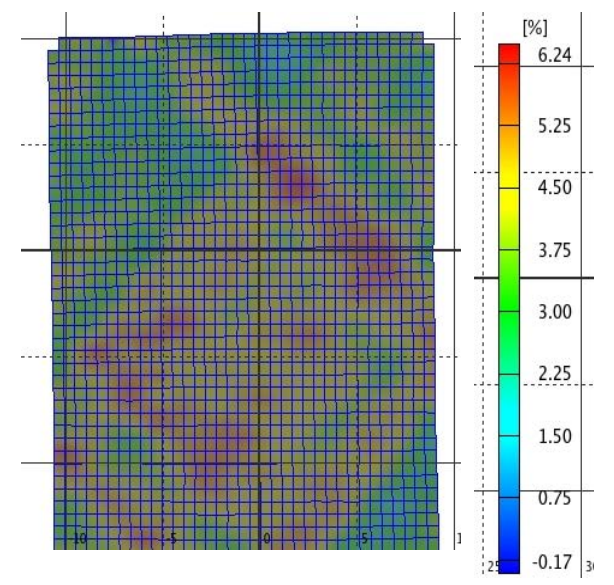

Figure 15. Tensile loading strain field at $4 \%$ global strain for a marine composite $\left(\varepsilon_{11}\right)$

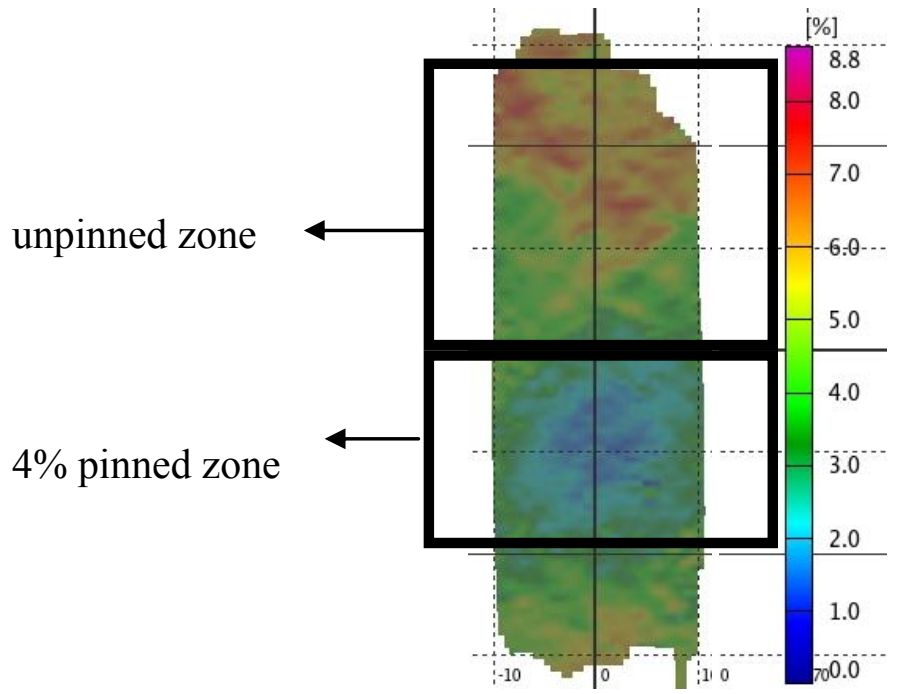

Figure 16. Tensile loading strain field at $4 \%$ global strain, pinned and unpinned zone for a marine composite $\left(\varepsilon_{11}\right)$

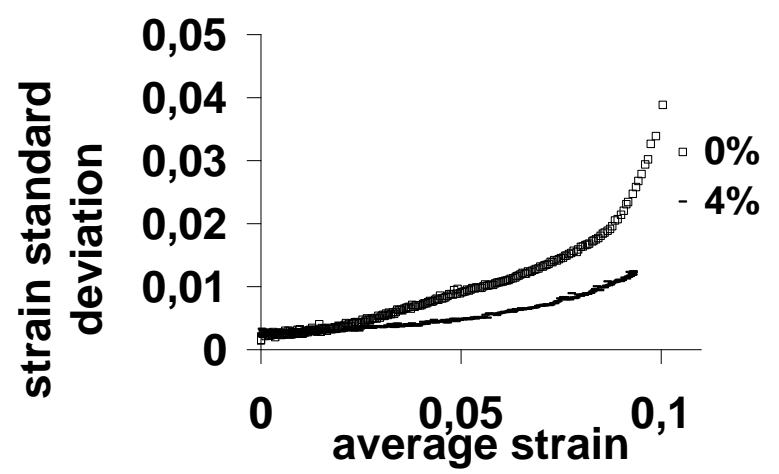

Figure 17. Average strain versus the strain standard deviation for the aeronautical composite 

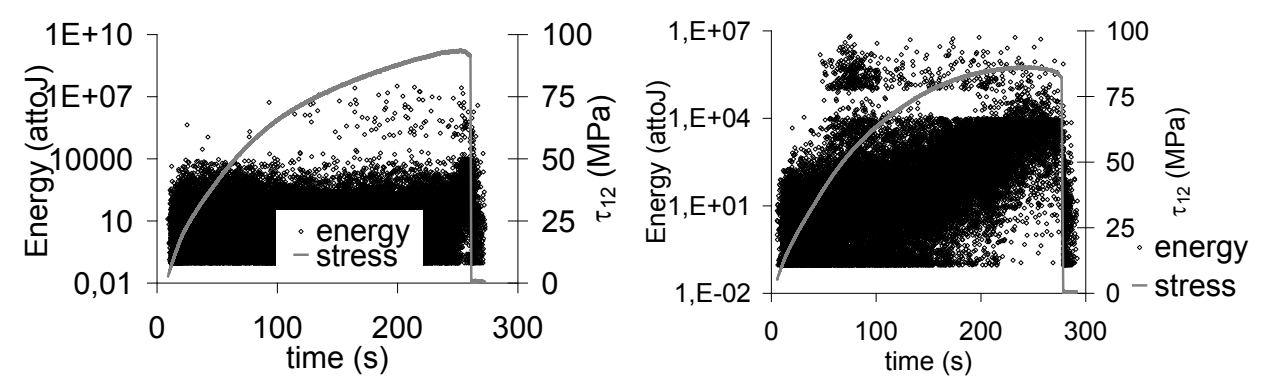

Figure 18. Acoustic emission energy variation a) unpinned composite b) pinned

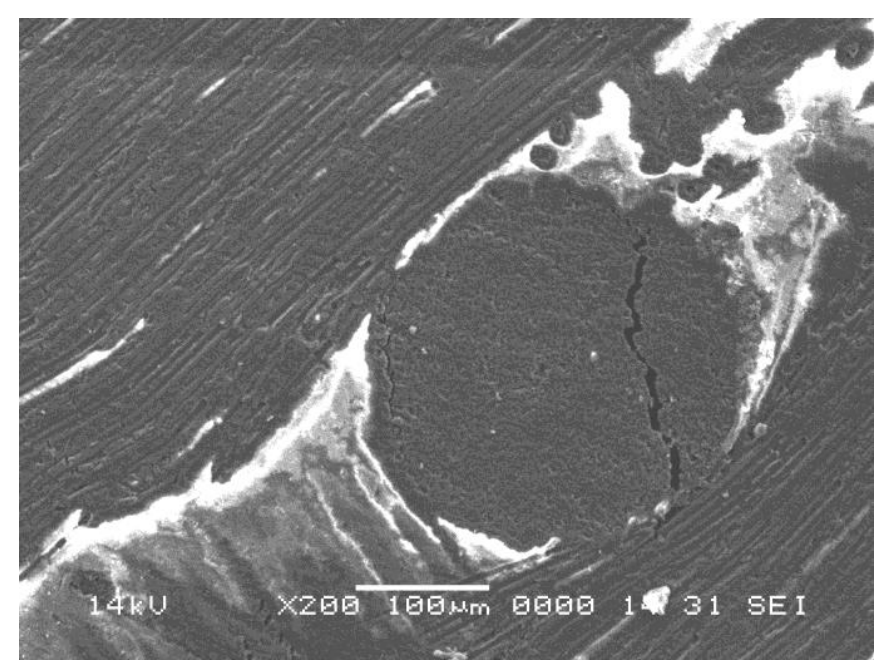

Figure 19. Pin cracking, tests in SEM, tensile load applied horizontally. 